\title{
Flora das cangas da Serra dos Carajás, Pará, Brasil: Alstroemeriaceae
}

\author{
Flora of the cangas of the Serra dos Carajás, Pará, Brazil: Alstroemeriaceae
}

Ana Kelly Koch ${ }^{1,2}$

\begin{abstract}
Resumo
Este trabalho apresenta um tratamento para Alstroemeriaceae das cangas da Serra dos Carajás, no estado do Pará, Brasil. Bomarea edulis é a única espécie registrada na área, sendo apresentados descrição, ilustrações e comentários morfológicos.
\end{abstract}

Palavras-chave: FLONA, monocotiledôneas, Pará, taxonomia.

\begin{abstract}
This paper presents a treatment for Alstroemeriaceae of the cangas of the Serra dos Carajás, in the Pará state, Brazil. Bomarea edulis was the only recorded species, and were provided a morphological description, as well illustrations and morphological comments.
\end{abstract}

Keywords: FLONA, monocots, Pará, taxonomy.

\begin{abstract}
Alstroemeriaceae
Alstroemeriaceae L. compreende os gêneros Alstroemeria L. (cerca de 125 espécies), Bomarea Mirb. (cerca de 122 espécies), Drymophila R.Br. (duas espécies), Luzuriaga Ruiz \& Pav. (quatro espécies) e Schickendantziella Speg. (uma espécie). As espécies da família são lianescentes ou herbáceas eretas, com rizoma simpodial, folhas alternas e ressupinadas e inflorescências terminais em cimeiras umbeliformes. As flores são trímeras, homoclamídeas, bissexuadas e vistosas, estames 6, ovário ínfero, e os frutos são do tipo cápsulaloculicida raramente indeiscente, com sementes globosas com ou sem sarcotesta. Os representantes da família encontram-se distribuídos nas Américas Central e do Sul, além das Ilhas do Caribe (Aagesen \& Sanso 2003), e crescem em solos oligotróficos de áreas florestadas, alagadas, campestres e desérticas (Aagesen \& Sanso 2003; Alzate et al. 2008; Assis 2012; Govaerts 2015). No Brasil ocorrem dois gêneros, amplamente distribuídos pelo país, ocorrendo em áreas antropizadas, com vegetação aberta, bem como em bordas ou interiores de florestas, sendo Alstroemeria com 43 espécies e Bomarea com apenas B. edulis (Tussac) Herb. (BFG 2015).

Na Serra dos Carajás apenas Bomarea edulis foi registrada, ocorrendo diretamente sobre as cangas.
\end{abstract}

\section{Bomarea Mirb.}

As espécies do gênero são geralmente ervas volúveis, com folhas papilosas na face abaxial, flores actinomorfas, infundibuliforme ou campanuladas, com as tépalas internas maculadas. As cápsulas têm deiscência valvar e as sementes apresentam sarcotesta roxo-alaranjada (Assis 2012). O gênero tem distribuição do México e Antilhas até o sul da América do Sul, com grande parte das espécies concentradas nos Andes da Colômbia até a Bolívia e apenas $B$. edulis tem distribuição neotropical, sendo a única de ocorrência no Brasil (Gereau 1994; Hofreiter 2008; BFG 2015).

1.1. Bomarea edulis (Tussac) Herb. Amaryllidaceae: 111. 1837. Figs. 1a-g; 2a-d

Planta até 1,5 m alt., caule glabro. Folhas oblongas a oblongo-lanceoladas, 11-11,5 × 1,5-3 $\mathrm{cm}$, ápice acuminado a cuspidado. Inflorescência 17-20 cm compr., laxo umbelada; brácteas 4-7,5 $\times 1-2 \mathrm{~cm}$. Flores pêndulas, 7-8,5 cm compr., rosaesverdeadas, creme ou amareladas; tépalas externas oblongas ou obovais, 2,8-3,5 × 0,8-1,2 cm, ápice acuminado, externamente róseas, internamente verde-rosadas com poucas máculas enegrecidas no ápice, tépalas internas espatuladas, ápice retuso ou

'Museu Paraense Emílio Goeldi, Coord. Botânica. Av. Perimetral, Terra Firme, 66077-830, Belém, PA, Brasil.

${ }^{2}$ Autor para correspondência: anakbio@gmail.com 

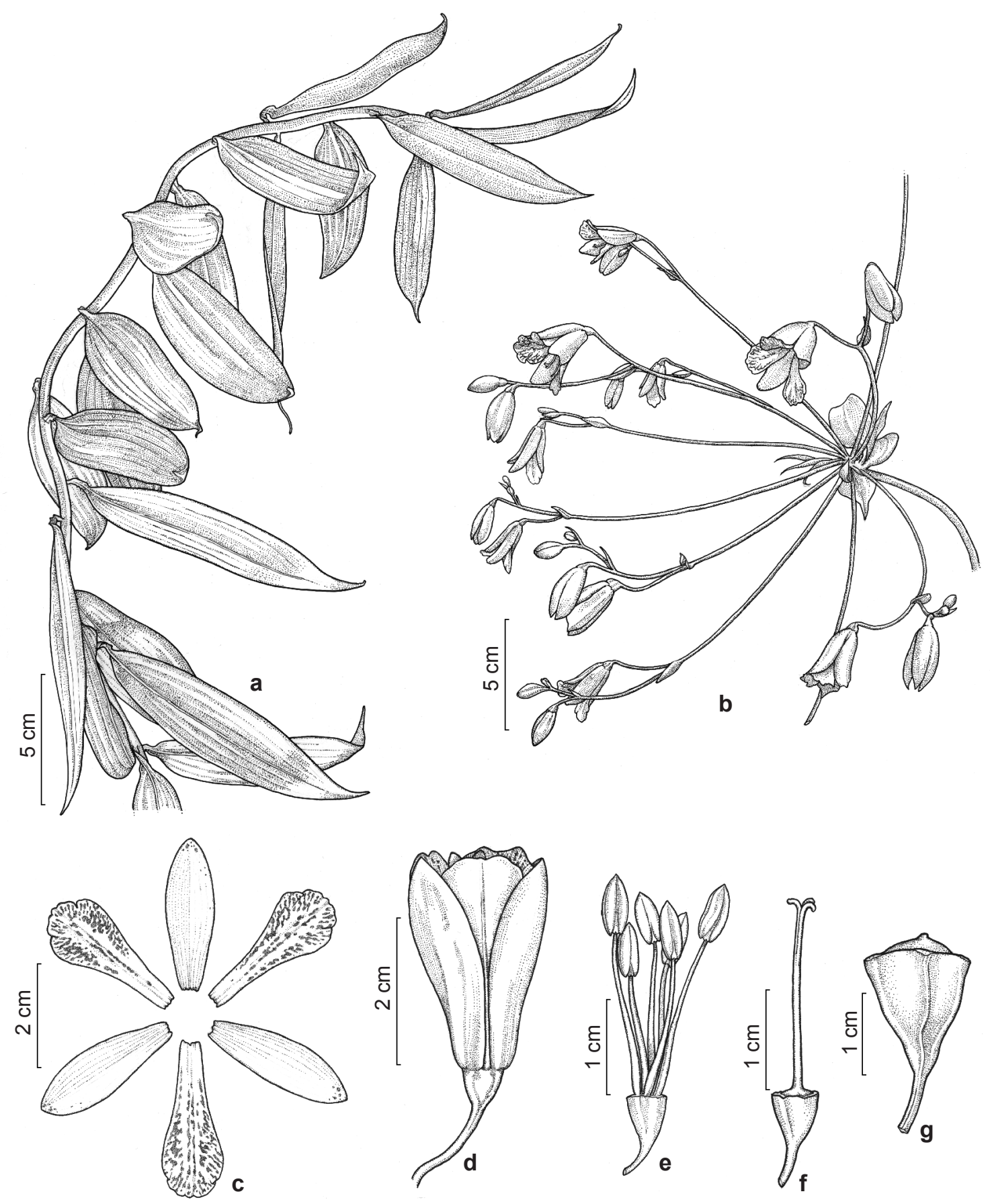

Figura 1 - Bomarea edulis - a. hábito; b. inflorescência; c. flor distendida; d. flor em vista lateral; e. androceu; f. gineceu; g. fruto (a-f. P.L. Viana et al. 4103; g. L.V.C. Silva et al. 1183).

Figure 1 - Bomarea edulis - a. habit; b. inflorescence; c. distended flower; d. flower in side view; e. androecium; f. pistil; g. fruit (a-f. P.L. Viana et al. 4103; g. L.V.C. Silva et al. 1183). 

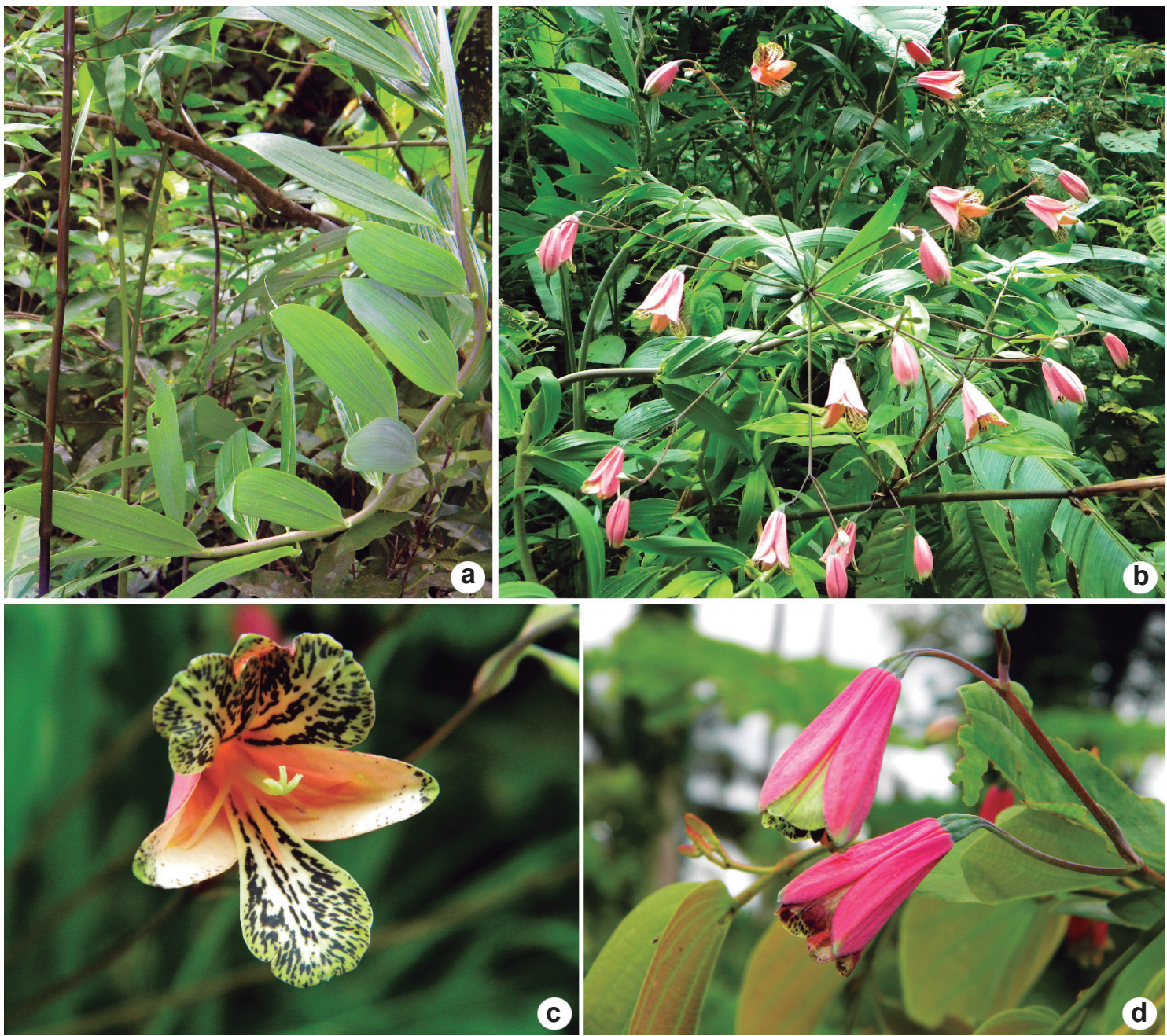

Figura 2-Bomarea edulis - a. hábito; b. inflorescência; c. flor em vista frontal; d. flor em vista lateral. (fotos Ana Kelly Koch) Figure 2 - Bomarea edulis - a. habit; b. inflorescence; c. flower in frontal view; d. flower in side view. (photos Ana Kelly Koch).

mucronado, $2,8-3,5 \times 0,5-0,8 \mathrm{~cm}$, externamente amarelo-esverdeadas, com nervura central rosada, internamente amarelo-esverdeadas com maculas avermelhadas e variegadas; estames $6,2,4-3 \mathrm{~cm}$ compr.; ovário 2,6 cm compr., estilete 2,5-3 cm compr. Cápsula imatura, $1,5-1,8 \mathrm{~cm}$ compr.

Material examinado: Canaã dos Carajás: Serra Sul, S11-B, 6020'40"S, 50²4'30"W, 687 M, 30.I.2012, fr., L.V.C. Silva et al. 1183 (BHCB); S11D, 6023'55"S, $50^{\circ} 16^{\prime} 39^{\prime \prime} \mathrm{W}, 700 \mathrm{~m}, 17 . \mathrm{III} .2009$, fl., P.L. Viana et al. 4103 (BHCB); Parauapebas: Serra Norte, N5, 601'62”S, $50^{\circ} 07^{\prime} 49^{\prime \prime} \mathrm{W}, 715 \mathrm{~m}, 27 . I V .2015$, fl., N.F.O. Mota et al. 2941 (MG).

Bomarea edulis tem ampla distribuição na região neotropical, e no Brasil ocorre em todas as regiões, não tendo sido registrada apenas para o Amapá e Roraima, ocorrendo no interior e bordas de florestas, além de áreas abertas como campinaranas, campos rupestres, restingas e afloramentos rochosos, porém restritas até 1000 $\mathrm{m}$ de altitude. Ao longo de sua distribuição possui variação morfológica nas partes vegetativas e também na coloração das flores (Alzate et al. 2008; Assis 2012; BFG 2015). Na Serra de Carajás foi encontrada nas Serras Norte e Sul, sempre sobre as cangas em locais mais sombreados na margem dos capões e da mata firme.

\section{Agradecimentos}

Agradecemos ao Museu Paraense Emílio Goeldi e ao Instituto Tecnológico Vale, a estrutura e o apoio fundamentais ao desenvolvimento desse trabalho. Aos curadores dos herbários consultados, o acesso aos materiais examinados. Ao ICMBio, especialmente ao Frederico Drumond Martins, 
a licença de coleta concedida e suporte nos trabalhos de campo. Ao MS João Silveira, a confecção da ilustração. Ao Programa de Capacitação Institucional (MPEG/MCTI), a bolsa concedida à autora. Ao Instituto Tecnológico Vale (01205.000250/2014-10) e ao CNPq (processo 455505/2014-4), o financiamento do projeto.

\section{Referências}

Asgesen, L. \& Sanso, M. 2003. The phylogeny of the Alstroemeriaceae based on morphology, rps 16 intron and rbcL sequence data. Systematic Botany 28: 47-69.

Alzate, F.; Quihano-Abril, M.A. \& Morrone, J.J. 2008. Panbiogeographical analysis of the genus Bomarea (Alstroemeriaceae). Journal of Biogeography 35: 1250-1257.
Assis, M.C. 2012. Alstroemeriaceae na Região Sul. Rodriguésia 63: 1117-1132.

BFG. 2015. Growing knowledge: an overview of Seed Plant diversity in Brazil. Rodriguésia 66: 1085-1113.

Gereau, R.E. 1994. Alstroemeriaceae. In: Davidse, G. Sousa, S.M. \& Chater. O.A. (eds.) Flora Mesoamericana, Alismataceae a Cyperaceae 6. Universidad Nacional Autónoma de México, México. Pp. 48-51.

Govaerts, R. 2015. Alstroemeriaceae. In: World checklist of selected plant families. Royal Botanic Garden, Kew. Disponível em <http://apps.kew. org/wcsp/qsearch.do>. Acesso em 14 dezembro 2015.

Hofreiter, A. 2008. A revision of Bomarea subgenus Bomarea s. str. section Multiflorae (Alstroemeriaceae). Systematic Botany 33: 661-684.

\section{Lista de exsicatas}

Mota, N.F.O. 2941 (1.1); Silva, L.V.C. 1183 (1.1); Viana, P.L. 4103 (1.1). 